\title{
The effect of the Protecting Life in Global Health Assistance policy in South Africa: Possible implications for local HIV/AIDS non-governmental organisations
}

\author{
F Jogee, LLB, LLM \\ Centre for the AIDS Programme of Research in South Africa (CAPRISA), University of KwaZulu-Natal, Durban, South Africa
}

Corresponding author: F Jogee (faadielajogee@gmail.com)

\begin{abstract}
The USA's Protecting Life in Global Health Assistance policy (PLGHA) became effective in 2017, prohibiting foreign non-governmental organisations (NGOs) from receiving US federal funding if they engage in termination of pregnancy (TOP) and/or TOP-related services, including counselling, referrals or lobbying, except under limited circumstances. Globally, the majority of federal funding supports HIV/ AIDS programmes, which are relied upon by a significant proportion of South Africans for treatment and care. Although HIV/AIDS NGOs do not provide TOP, some of their programmes may involve TOP-related services and activities prohibited by PLGHA, which could result in the complete defunding of these organisations. This article provides examples of how HIV/AIDS NGOs could violate the PLGHA through specific programme activities, and provides recommendations on how to prevent such violations.
\end{abstract}

S Afr J Bioethics Law 2019;12(1):38-43. DOI: 10.7196/SAJBL.2019.v12i1.645

The USA's Protecting Life in Global Health Assistance policy (PLGHA) is an expansion of the Mexico City Policy (MCP), which prohibited foreign NGOs that provide termination-of-pregnancy (TOP) services or actively promote TOP as a family-planning method from receiving US federal funding for family planning programmes. The expanded programme came into global effect in 2017..$^{[1-7]}$ PLGHA affects a number of major US funding agencies responsible for providing the majority of foreign health assistance to sub-Saharan Africa. ${ }^{[5,8]}$ PLGHA proscribes TOP and TOP-related services, including counselling, referrals or lobbying, with only rare exceptions, and extends to global health assistance programmes that include HIV/AIDs programmes - unlike MCP, which was limited to family-planning assistance. ${ }^{[6]}$ Ostensibly, HIV/AIDS programmes would not be affected by PLGHA, since HIV/AIDS NGOs are not TOP providers. However, numerous HIV/AIDS programmes provide information on sexual and reproductive healthcare that may include TOP-related services or activities prohibited by PLGHA. South Africa (SA) is shouldering the highest HIV burden in the world, and many South Africans rely on treatment programmes provided by SA HIV/AIDS NGOs. The majority of funding received by these NGOs to support HIV/AIDS programmes is funded by the US government. ${ }^{[9,10]}$ Consequently, SA HIV/AIDS NGOs receiving US foreign assistance are required to comply with PLGHA in order to continue to receive funding for their HIV/AIDS programmes. This article explains PLGHA and how it might affect funding for HIV/AIDS in SA by illustrating how certain programmes and activities of HIV/AIDS NGOs can violate the provisions of PLGHA, and suggests ways in which such NGOs can prevent jeopardising their funding.

\section{The Mexico City Policy}

The MCP was instituted by the Reagan administration in 1984, during President Reagan's visit to the second International Conference on
Population in Mexico City. ${ }^{[1,2]}$ MCP was founded on the obligation to legally safeguard the life of a child 'before it is born as well as after birth', as enshrined in the United Nations' Declaration of the Rights of the Child. ${ }^{[3]}$ The principle objective of MCP was to promote the adoption of 'sound economic policies and where appropriate, population policies consistent with respect for human life and family values' in developing countries..$^{[2]}$ US support for family planning programmes is predicated on safeguarding and upholding human life and human dignity, and supporting families. ${ }^{[2]}$ The USA at the time deemed TOP unacceptable, rejecting its use as a conventional family planning method..$^{[2]}$ Accordingly, NGOs that either provided or actively endorsed TOP were precluded from receiving any family planning funding from the US government. ${ }^{[2]}$ Since its implementation 35 years ago, MCP has been rescinded and reinstated several times, but been in effect for at least 18 years.

\section{Protecting Life in Global Health Assistance}

US President Donald Trump reinstated and expanded MCP, retitling it Protecting Life in Global Health Assistance (PLGHA), in 2017. ${ }^{[1,4]}$ PLGHA compels foreign NGOs applying for global health assistance, including HIV and tuberculosis (TB) programmes, to certify their compliance with PLGHA to receive US federal funding. ${ }^{[1]}$ PLGHA affects the funding administered by the US Agency for International Development (USAID), US Department of State (DoS), US Department of Defence, the US President's Emergency Plan for AIDS Relief (PEPFAR), the Centers for Disease Control (CDC) and the National Institutes of Health $(\mathrm{NIH}) \cdot{ }^{[5]}$ It affects three specific categories of funding agreements: contracts, co-operative agreements and grants. ${ }^{[5]}$ PLGHA applies to all foreign NGOs, including international and regional NGOs based abroad, and US NGOs based in foreign countries receiving assistance. ${ }^{[1]}$ While US 
NGOs are not expected to comply with PLGHA, foreign sub-recipients of a US primary recipient must certify their compliance with PLGHA prior to receiving assistance from the US NGO. ${ }^{[1]}$

PLGHA prohibits all foreign NGOs that are recipients and sub-recipients of federal funding from performing or 'actively promot[ing] abortion as a method of family planning in foreign countries or provid[ing] financial support to any other foreign NGO that conducts such activities.' ${ }^{\prime[6]}$ 'Abortion as a method of family planning' is defined as the procurement of a TOP with the intention of 'spacing births.' TOP on the grounds of fetal abnormality or the mental or physical health of the pregnant woman is included in this definition. However, TOP procured on the grounds of rape, incest or life endangerment is excluded from this definition, and does not violate the provisions of the policy. ${ }^{[6]}$ 'To perform abortions' is defined as the management of a facility that permits and provides TOP. Post-TOP care for any adverse effects resulting from 'legal or illegal abortions' is excluded from this definition. ${ }^{[6]}$ To actively 'promote abortion' refers to an organisation allocating 'resources, financial or other, in a substantial or continuing effort to increase the availability or use of abortion, ${ }^{\prime[6]}$ including:

- running regular programmes providing advice, counselling and information relating to the availability and advantages of TOP.

- advising women on the availability of TOP or promoting TOP. However, 'passively responding' to an inquiry about where a woman can safely and legally procure a TOP is not considered active promotion of TOP. PLGHA does not explicitly state what constitutes a passive response; however, it specifies that in order to provide a passive response, a pregnant woman must pose the specific question after declaring that she is going to legally terminate her pregnancy, and the healthcare provider is ethically required to provide information on where to safely and legally procure TOP.

- campaigning for the legalisation or availability of TOP by foreign governments, or lobbying to safeguard and uphold the legality of TOP.

- leading campaigns to inform the public of the advantages and/or availability of TOP. ${ }^{[6]}$

Referrals for TOP on the grounds of rape, incest or life endangerment as a result of carrying the fetus to term, and any resultant post-TOP treatment, do not constitute active promotion of TOP. ${ }^{[6]}$ If a staff member of an NGO acts in his or her individual capacity and engages in the activities proscribed by PLGHA outside of the NGO in their personal time, the NGO will not be in violation of PLGHA. ${ }^{[6]}$

Importantly, PLGHA mentions that:

'In the event of a conflict between a term of this paragraph (a) and an affirmative duty of a healthcare provider required under local law to provide counselling about and referrals for abortion as a method of family planning, compliance with such law shall not trigger a violation of this paragraph (a).[6]

PLGHA's implementation plan took effect on 15 May 2017. ${ }^{[7]}$ Consequently, the departments and agencies affected by PLGHA were required to revise all relevant funding agreements to ensure compliance with PLGHA. ${ }^{[7]}$ Accordingly, PLGHA does not apply retroactively to funds received prior to its effect. However, all funds provided after its implementation will be affected. Therefore, although a grant, contract or agreement may have been accepted prior to PLGHA, if funding is dispensed annually, funds received after it has been effected will be subject to PLGHA.

\section{Global health assistance in South Africa}

In 2017, the US contributed 33\% (approximately USD12.4 billion) of global development health assistance. ${ }^{[8]}$ International NGOs received approximately USD829 million in health assistance in 2017..$^{[8]}$ Of this, 46\% (USD6.5 billion) was allocated to sub-Saharan Africa. ${ }^{[8]}$ PLGHA will affect approximately USD8.8 billion in foreign assistance, and approximately $70 \%$ of this US federal funding is allocated to PEPFAR ${ }^{[9]}$ SA NGOs receive an estimated $60 \%$ of their funding from the USA through PEPFAR. ${ }^{[9,10]}$ Therefore the likelihood of national NGOs denouncing PLGHA and forgoing US federal funding is low, given the high proportion of funding received. ${ }^{[9,10]}$ In 2017, approximately USD470 million in foreign assistance was allocated to SA, of which more than USD274 million was received by SA NGOs. ${ }^{[9]}$ There were over 4.3 million South Africans receiving antiretroviral treatment (ART) in 2017, with over $86 \%$ of these relying on local NGOs to access it, while $88 \%$ of women receiving ART in prevention of mother-to-child transmission programmes obtained treatment from local NGOs. ${ }^{[9]}$ According to the US government, USD510.47 million in foreign assistance is planned for SA for the fiscal year 2019. [11] An estimated USD509.60 million is allocated towards health assistance, principally for HIV/AIDS (USD500 million) and TB (USD9.6 million,) ${ }^{[11]}$ given that the country has the highest burden of HIV/AIDS in the world, and is currently facing a TB crisis. ${ }^{[12,13]}$

\section{PLGHA and TOP laws}

PLGHA condones TOP when pregnancy is life-threatening, or a result of rape or incest. ${ }^{[6]}$ This exception partially correlates with the SA Choice on Termination of Pregnancy Act No. 92 of 1996 (CTOPA). ${ }^{[14]}$ Section 2(1) of CTOPA outlines the legal grounds for TOP in SA. Under Section 2(1)(b), TOP is permitted between 13 and 20 weeks' gestation if a medical practitioner, in consultation with the woman concerned, believes that the pregnancy: has resulted from rape or incest; may threaten the physical or mental health of the woman; will result in mental or physical fetal abnormality; or will negatively impact the woman's socioeconomic standing. ${ }^{[14]}$ All of these grounds except the first are prohibited by PLGHA. Under section 2(1)(c) of CTOPA, TOP is permitted after 20 weeks' gestation if a medical practitioner, in consultation with another medical practitioner or a registered midwife, believes: continued pregnancy is life-threatening; ${ }_{i}^{[18]}$ there is severe fetal malformation; or there is substantial risk of injury to the fetus. No provision is made for the last two grounds for TOP in PLGHA, or for TOP on request in the first trimester, which is permitted under section 2(1)(a) of CTOPA. ${ }^{[14]}$

If a pregnancy precipitates an emergency, SA healthcare providers are legally and ethically obligated to administer emergency medical care to prevent grievous harm or death to the patient, including TOP. ${ }^{[15,16]}$ Moreover, a healthcare provider cannot object to performing TOP in an emergency context unless there is another healthcare provider available and willing to perform the TOP, in which case referral of the patient to this colleague is acceptable. ${ }^{[15]}$ In this instance, there will be no violation of PLGHA. The following discussion concerns non-emergency circumstances. 
In any country where PLGHA is applicable, the policy does not apply to healthcare providers who have a legal duty in that country to refer or counsel patients on TOP. ${ }^{[6]}$ Currently in SA law, CTOPA does not obligate healthcare providers to provide counselling to women, although section 6 states that healthcare providers should encourage 'non-mandatory and non-directive' pre- and post-TOP counselling. ${ }^{[17]}$ CTOPA clearly states that all women requesting a TOP, on any of the grounds listed under section 2(1), from either a medical practitioner or a registered midwife must be informed of their rights. ${ }^{[18]}$ Therefore, there is no explicit legal duty upon healthcare providers to refer a woman to a TOP facility if she has not requested a TOP under any of the grounds listed in section 2(1) of CTOPA. However, section 6 may be fulfilled by providing the woman with information on TOP, including its availability, accessibility and/ or benefits, since withholding such information from a woman requesting a TOP will deny her of her right to make an informed reproductive healthcare decision, and subsequently to receive such healthcare, both of which are Constitutional rights to which she is entitled. ${ }^{[19,20]}$ Nevertheless, CTOPA does not clearly state how section 6 can be fulfilled, as providing women with information about the availability and/or benefits of TOP, as well as referrals to TOP facilities, could still be deemed to be promotion of TOP as a method of family planning under PLGHA, if a woman does not request a TOP as per section 2(1). Therefore, although there is an ethical duty to provide women with information on where to legally procure a safe TOP and counselling, there is no clear legal duty for healthcare providers to provide information regarding the availability and/or benefits of TOP, or to provide referrals, to women who are merely asking what their options might be regarding TOP, and not requesting a TOP in terms of section 2(1). ${ }^{[21]}$

This is important because although HIV/AIDS NGOs usually do not provide TOP services, they may implement sexual and reproductive health (SRH) programmes focused on upholding and promoting sexual and reproductive health rights (SRHR). This includes the right to make autonomous decisions on matters affecting SRH, and SRH programmes include information on the right to access sexual and reproductive health services (SRHS). ${ }^{[22]}$ Therefore it is not uncommon for these programmes to discuss women's rights regarding TOP, including information on its availability and accessibility, and/or the potential benefits of safe and legal TOP. In this context, it is unlikely that a woman would request a TOP in terms of section 2(1) from an HIV/AIDS NGO itself, but rather directly from a family planning and reproductive health NGO, such as Marie Stopes, which is not federally funded in SA.

\section{HIV/AIDS NGOs and PLGHA}

To look at these issues in more specific detail, several local federally funded HIV/AIDS NGOs have developed and implemented programmes or are engaged in research activities that may violate the provisions of PLGHA. The AIDS Foundation of SA (AFSA) is supported by PEPFAR, and is concerned with the prevention and treatment of HIV/AIDS. ${ }^{[23]}$ AFSA may be affected by PLGHA via its social and behaviour change $(\mathrm{SBC})^{[24]}$ and SRHR programmes. ${ }^{[25]}$ The SBC programme is targeted towards adolescent girls and young women (AGYW) between 15 and 24 years old, and its primary goals are to reduce risky sexual behaviour and decrease the rates of HIV infection and teenage pregnancy among this group. ${ }^{[25]}$ AFSA develops and fosters 'resilience, self-confidence, self-esteem and self-efficacy' and the 'knowledge, attitudes and skills' to prevent risky sexual behaviour and engage in positive behaviours and practices concerning sexual health ${ }^{[24]}$ It further strives to improve communication regarding SRH between children and their parents. ${ }^{[24]}$ TOP is an important topic in women's $\mathrm{SRH}$, and therefore the provision of relevant information to AGYW is likely. The SRHR programme focuses on tackling and redressing the cultural, legal, social and structural barriers to SRHR among marginalised communities. The programme was founded in 2014 and is funded by the Swedish International Development Agency (SIDA). ${ }^{[25]}$ One of the primary objectives of the programme is to assist and inform 'target marginalised populations' with regard to overcoming obstacles to adolescent SRHS, including safe and legal access to TOP. This provision of information is prohibited by PLGHA.

ANOVA Health Institute is an HIV research NGO, funded by PEPFAR, USAID and the CDC, which specialises in HIV and TB treatment and care, and clinical and social research. ANOVA may be impacted by PLGHA by way of its My Future First campaign. ${ }^{[26]}$ The campaign is a component of the DREAMS programme, the objective of which is to empower AGYW to become 'determined, resilient, empowered, AIDSfree, mentored and safe' women through specific health measures tailored to their age group. ${ }^{[26]}$ My Future First seeks to uphold the SRHR of AGYW via the provision of information and contraception, with the aim of preventing unplanned pregnancies, sexually transmitted infections and HIV infection. ${ }^{[26]}$

HIVSA is a non-profit organisation that seeks to assist those afflicted with HIV/AIDS, and is funded by PEPFAR and USAID. HIVSA aims to achieve an 'HIV-free generation' by enabling community workers, individuals and organisations with the skills to overcome the health and socioeconomic factors exacerbating the HIV/ AIDS burden. ${ }^{[27]}$ HIVSA also currently participates in the DREAMS programme. ${ }^{[28]}$ HIVSA, via the DREAMS programme, aims to identify and address barriers that increase AGYW's vulnerability to HIV transmission and infection, such as poverty, sexual violence, gender inequality and lack of education. DREAMS, which facilitates the provision of SRHR information on preventing unplanned pregnancy, provides services to address these barriers. ANOVA's and HIVSA's involvement in DREAMS therefore probably includes provision of information on the availability and/or benefits of safe and legal TOP, which is prohibited by PLGHA.

Mothers2Mothers is funded by USAID and PEPFAR, and collaborates with local governments, communities and partners to attempt to eliminate HIV infection among children, decrease mortality rates in mothers and children and endorse 'universal access to reproductive health and family planning.'[29] Mothers2Mothers assists AGYW by endorsing HIV counselling and testing (HCT), and SRH education in schools, youth clubs and the general community. ${ }^{[29]}$ It also provides referrals to AGYW in need of healthcare services pertaining to HCT and SRH.

The Networking HIV \& AIDS Community of Southern Africa (NACOSA) comprises more than 1500 civil society organisations with the shared goal of eliminating HIV/AIDS and TB in the southern African region. ${ }^{[30]}$ The organisation is supported by PEPFAR and USAID. NACOSA's Young Women and Girls Programme was established to provide a broad set of education, health and support services tailored for AGYW, including community-based HCT, TB screening and SRH education and services. ${ }^{\left[{ }^{[0]}\right.}$ Mothers2Mothers and NACOSA programmes 
could also violate PLGHA, as they include SRH education and services, which are likely to involve the dissemination of information on the accessibility, availability and/or benefits of safe and legal TOP.

In accordance with PLGHA rules, for a healthcare provider to provide a woman with information regarding TOP, including its availability and/or benefits, the woman is required to ask the healthcare provider directly for the information she requires. ${ }^{[6]}$ She must expressly declare that she has already decided to terminate her pregnancy, and only thereafter, if she asks where to safely and legally procure a TOP, may the healthcare provider answer her question by providing her with the necessary information. ${ }^{[6]}$ Therefore, if a non-pregnant woman asks for information about TOP, or a pregnant woman who is unsure as to whether she wants to terminate her pregnancy asks what her options are with regards to TOP in a non-emergency context where her life is not in danger, or where her pregnancy was not a product of rape or incest, the healthcare provider is prohibited from providing her with the information under the provisions of PLGHA. In a non-emergency context, if a woman does not specifically request a TOP, in terms of section 2(1) of CTOPA, ${ }^{[14]}$ the healthcare provider is not explicitly legally obligated to inform her of all her rights under the Act, and since there is no legal duty to counsel or refer her to TOP facilities, the healthcare provider may not provide information on TOP. ${ }^{[6]}$

Therefore, the educational and informative components of SRH and SRHS programmes implemented by AFSA, ANOVA, HIVSA, Mothers2Mothers and NACOSA that include TOP information and referrals are prohibited, unless they fall within the confines of the exceptions of PLGHA, since there is no overt legal implication in place via CTOPA. Furthermore, while these NGOs and their programmes may not be funded entirely by the USA, PLGHA clearly states that no funding, irrespective of the source, can be used for activities proscribed by PLGHA without placing an organisation at risk of being defunded ${ }^{[5]}$ Moreover, even if the programmes were approved by US funders and implemented before the enactment of PLGHA, if funds are being provided annually and are dispensed to these NGOs after the enactment of PLGHA, that funding will be affected by the provisions of PLGHA. For instance, AFSA's SRHR programme began in 2014 and is still active, and therefore it is probably still receiving money from SIDA to provide TOP-related services and activities which are now prohibited by PLGHA. Therefore, any US funding received by AFSA since PLGHA was enacted could be revoked if the organisation violates the provisions of the policy through the SRHR programme, even though it was first implemented before PLGHA and is SIDA-funded.

Research institutions may also be affected by PLGHA. The Centre for the Aids Programme of Research in South Africa (CAPRISA) conducts'globally relevant and locally responsive research' towards the understanding of HIV prevention and epidemiology, HIV pathogenesis and HIV and AIDS treatment. ${ }^{[3]}$ CAPRISA operates three established research clinics. The eThekwini clinic, attached to the Prince Cyril Zulu Communicable Disease Centre, is Durban's 'largest government outpatient TB and sexually transmitted diseases' treatment facility. ${ }^{[32]}$ The Springfield clinic hosts TB clinical studies, and is connected to King Dinuzulu Hospital, which specialises in treating patients with drug-resistant TB. The Vulindlela clinic is a research clinic with an adolescent-friendly clinic on its premises that locals rely upon for healthcare. ${ }^{[32]}$ CAPRISA and its research studies are predominantly funded by the US government. ${ }^{[3-35]}$ CAPRISA's funding may be jeopardised if a woman presents herself at any of CAPRISA's clinic sites and requests information about TOP or TOP facilities, without declaring that she is pregnant and has decided to have a TOP. The healthcare provider attending to her cannot provide the patient with a TOP referral or TOP-related information, unless the patient has stated that her life is at risk or that her pregnancy is a result of rape or incest.

Wits [University of the Witwatersrand] Reproductive Health and HIV Institute (Wits RHI) specialises in 'HIV, sexual reproductive health and vaccine-preventable diseases. ${ }^{\prime[6]}$ Among its list of partners and donors are PEPFAR, USAID, NIH, CDC and NACOSA. ${ }^{[37]}$ Wits RHI is currently working with the HIV Prevention Trial Network (HPTN) on the HPTN 084 study. ${ }^{[38]}$ This study will assess the 'safety and efficacy' of long-acting cabotegravir, an injectable, together with tenofovir disoproxil fumarate/emtricitabine, an oral tablet, for PrEP in HIVnegative women. ${ }^{[38]}$ The study is currently enrolling women from sub-Saharan Africa between the ages of 18 and 45 years old who are vulnerable to HIV infection. The results of this study could be significant in increasing adherence to PrEP. ${ }^{[38]}$ Pregnant women are excluded from the study, as it involves contraception. Therefore, if a research participant becomes pregnant during the trial and personally informs a site clinician of her pregnancy, or a blood sample taken from a research participant for the purposes of the study reveals an incidental finding that she is pregnant, and the participant requests TOP-related information without stating that she wants a TOP or that her pregnancy resulted from rape or incest or that her life might be threatened by the pregnancy, the site clinician cannot fulfil her request.

Although this sample is only a small snapshot of the ways in which HIV/AIDS NGOs could be affected, it is known that many local HIV/ AIDS NGOs are heavily reliant on US federal funding, and many South Africans rely on these NGOs for ART, PrEP, TB treatment and a host of health-related services, including SRHS. Therefore any minor violation of PLGHA resulting from a programme or activity facilitated by one of these NGOs, whether it is US federally funded or not, could defund an entire organisation, which could halt life-saving treatment, services and research focusing on SA's most vulnerable populations, and hinder any progress towards an AIDS-free generation. Accordingly, it is crucial that staff are informed and educated about PLGHA, and trained on how to identify and manage possible violations of the policy.

\section{Recommendations}

It is recommended that all US federally funded HIV/AIDS NGOs inform and educate all staff members, particularly healthcare providers, on PLGHA, paying careful attention to its proscribed activities and the exceptions to those proscriptions. Educating and informing staff members is of vital importance, as staff may erroneously believe that since HIV/AIDS NGOs do not focus predominantly on family planning, and do not engage in the provision of TOP, they will not be affected by PLGHA. More importantly, informing and educating staff members will assist them in identifying possible violations of PLGHA. It is recommended that to ensure compliance with PLGHA, each NGO should implement a policy on how to manage requests for information about TOP that do not fall within the exceptions of PLGHA, as this may be the most common potential violation facing staff members through programmes and activities. HIV/AIDS NGOs should ensure that staff faced with such requests have been trained 
to refer women to public health facilities funded by the relevant provincial Department of Health (DoH). All of the aforementioned NGOs are partnered with or associated with relevant provincial DoHs. ${ }^{[23,26,27,29-31,37]}$ NGOs should develop and implement referral programmes with their closest $\mathrm{DoH}$ facilities known to provide the information or services the women need regarding TOP. This should be done using the Bhekisisa \#SizeMap. ${ }^{[39]}$ This maps free TOP service providers, and provides the most up-to-date list of public health facilities actively providing TOP services. The NGOs should then follow up with the DoH facilities and the individual women, to ensure that they have received the information and/ or services required. Additionally, healthcare providers may still assist women outside of their employment in their personal and individual capacities, as long as this not done on the premises of their employer organisation.

\section{Conclusion}

SA requested USD309.6 million in foreign assistance in 2018, and is expected to receive over USD500 million for 2019. ${ }^{[11]}$ Presently, local HIV/ AIDS NGOs receive approximately $60 \%$ of US foreign assistance. ${ }^{[9,11]} \mathrm{HIV} /$ AIDS NGOs provide treatment for more than $85 \%$ of the South Africans living with HIV. ${ }^{[9]}$ PLGHA has proscribed TOP and TOP-related services, including counselling, referrals or lobbying, except under limited circumstances ${ }^{[6]}$ Failure to comply with the PLGHA could defund entire NGOs irrespective of whether the proscribed activities are themselves supported by federal funds. Several federally funded HIV/AIDS NGOs, including AFSA, ANOVA, HIVSA, Mothers2Mothers and NACOSA, have established and are currently implementing SRH programmes that inform and educate AGYW on SRHR, which are likely to include TOP and its availability. Research institutes including CAPRISA that have established research clinics connected with hospitals that provide SRHS might be approached by patients requesting TOP information from clinic staff, while study participants who become pregnant during research studies conducted by Wits RHI may approach study clinicians requesting TOP-related information, and their questions cannot be answered unless certain criteria implemented by PLGHA are met. It is recommended that all federally funded NGOs inform and educate all stuff members on PLGHA in relation to national law, which will assist them in identifying possible violations of PLGHA. NGOs should train staff on how to manage potential violations of PLGHA in the form of requests for TOP information, as this is potentially the most common violation. NGOs should refer women to relevant provincial $\mathrm{DOH}$ facilities that are actively providing the TOP-related services these women require. ${ }^{[39]}$ Subsequently, NGOs should follow up with the $\mathrm{DoH}$ facilities and the women to ensure that their requests were met. Lastly, healthcare providers should be aware that they may still assist women outside of their employment in their personal and individual capacities, as long as this does not take place on the premises of their employer organisation.

\author{
Acknowledgements. None. \\ Author contribution. Sole author. \\ Funding. None. \\ Conflicts of interest. None.
}

1. US Department of State. Protecting life in global health assistance. May 15, 2017. https://www.state.gov/r/pa/prs/ps/2017/05/270866.htm (accessed 17 November 2017).
2. USA. Policy statement of the United States of America at the United Nations International Conference on Population (second session), Mexico, DF, August 6 - 14, 1984. https://www.uib.no/sites/w3.uib.no/files/attachments/mexico_city_ policy_1984.pdf (accessed 22 October 2018).

3. United Nations General Assembly. Declaration of the rights of the child. General Assembly Resolution 1386 (XIV) of 20 November 1959. https://www.unicef.org/ malaysia/1959-Declaration-of-the-Rights-of-the-Child.pdf (accessed 22 October 2018).

4. Trump, DJ. Presidential memorandum regarding the Mexico City Policy. 23 January 2017. https://www.whitehouse.gov/the-press-office/2017/01/23/presidentialmemorandum-regarding-mexico-city-policy (accessed 17 November 2017).

5. The Henry J. Kaiser Family Foundation. The Mexico City Policy: An explainer. Fact sheet May 2018. http://files.kff.org/attachment/Fact-Sheet-The-Mexico-City-PolicyAn-Explainer (accessed 22 October 2018).

6. Department of Health and Human Services, USA. HSS Protecting Life in Global Health Assistance (May 2017). https://hab.hrsa.gov/fundingopportunities/ protectinglifeinglobalhealthassistancehhsmay2017.pdf (accessed 22 October 2018).

7. USAID. Standard provisions for US non-governmental organisations: A mandatory reference for ADS chapter 303 ADS. March 3, 2018. https://www.usaid.gov/sites/ default/files/documents/1868/303maa.pdf (accessed 24 October 2018).

8. Institute for Health Metrics and Evaluation, University of Washington. Financing global health 2017. Funding universal health coverage and the unfinished HIV/ AIDS agenda. 2018. http://www.healthdata.org/sites/default/files/files/policy report/FGH/2018/FGH_2017_full-report.pdf (accessed 24 October 2018).

9. Foundation for AIDS Research. Impact of Mexico City Policy on PEPFAR. Issue Brief, July 2018. https://www.amfar.org/uploadedFiles/_amfarorg/Articles/On_The_ Hill/2017/IB-Mexico-City-Policy-PEP-B-071818.pdf (accessed 24 October 2018).

10. Sherwood J, Sharp A, Honermann B, et al. Mapping the impact of the extended Mexico City Policy for HIV/family planning service integration in PEPFAR-supported countries: A risk index. BMC Pub Health 2018;18:1116. https://doi.org/10.1186/ s12889-018-6008-2

11. ForeignAssistance.gov. Map of foreign assistance worldwide. 2019. https://www. foreignassistance.gov/explore (accessed 24 October 2018).

12. Joint United Nations Programme on HIV and AIDS. Ending AIDS: Progress towards the 90-90-90 targets. UNAIDS, 2017. http://www.unaids.org/sites/default/files/ media_asset/Global_AIDS_update_2017_en.pdf (accessed 24 October 2018).

13. World Health Organization. Global Tuberculosis Report. Geneva:WHO, 2017. http:// apps.who.int/iris/bitstream/10665/259366/1/9789241565516-eng.pdf?ua=1 (accessed 24 October 2018).

14. South Africa. The Choice on Termination of Pregnancy Act No. 92 of 1996, section 2.

15. McQuoid-Mason D. State doctors, freedom of conscience and termination of pregnancy revisited. S Afr J Bioethics Law 2010;3(2):75-78.

16. South Africa. The Constitution of the Republic of South Africa Act No. 108 of 1996. Section 27(3).

17. South Africa. The Choice on Termination of Pregnancy Act No. 92 of 1996, section 4.

18. South Africa. The Choice on Termination of Pregnancy Act No. 92 of 1996, section 6.

19. South Africa. The Constitution of the Republic of South Africa Act No. 108 of 1996. Section 12(2)(a).

20. South Africa. The Constitution of the Republic of South Africa Act No. 108 of 1996. Section 27(1)(a).

21. Health Professions Council of South Africa. Guidelines for good practice in the healthcare professions. General ethical guidelines for reproductive health (2nd edition). Booklet 8. Pretoria: HPCSA, September 2016. http://www.hpcsa.co.za/ Uploads/editor/UserFiles/conduct_ethics/Booklet\%208\%20.pdf (accessed 30 October 2018)

22. Amnesty International USA. Sexual and reproductive health rights. https:// www.amnestyusa.org/pdfs/SexualReproductiveRightsFactSheet.pdf (accessed 30 October 2018).

23. AIDS Foundation of South Africa. About us. https://www.aids.org.za/partners (accessed 26 October 2018).

24. AIDS Foundation of South Africa. AFSA Programme: Ikusasa. https://www.aids.org za/programme/ikusasa/ (accessed 26 October 2018).

25. AIDS Foundation of South Africa. AFSA Programme: Sexual and Reproductive Health Rights. https://www.aids.org.za/programmes/sexual-reproductive-healthrights (accessed 26 October 2018).

26. ANOVA Health Institute. Campaigns. https://www.anovahealth.co.za/campaigns/ (accessed 26 October 2018).

27. HIVSA. Who we are. http://hivsa.com/?q=tags/who-we-are (accessed 26 October 2018).

28. HIVSA. DREAMS. http://hivsa.com/?q=content/dreams (accessed 26 October 2018).

29. Mothers2Mothers. Where we work. South Africa. https://www.m2m.org/wherewe-work/south-africa/.

30. NACOSA. Programmes. www.nacosa.org.za/about/programmes/ (accessed 26 October 2018) 
31. Centre for the AIDS Programme of Research in South Africa. Founding. https:// www.caprisa.org/Pages/Founding (accessed 24 October 2018).

32. Centre for the AIDS Programme of Research in South Africa. Research clinics. https://www.caprisa.org/Pages/ResearchClinics (accessed 24 October 2018).

33. Centre for the AIDS Programme of Research in South Africa. Financial statements. https://www.caprisa.org/Pages/FinancialStatments (accessed 24 October 2018).

34. Centre for the AIDS Programme of Research in South Africa. CAPRISA Studies. https://www.caprisa.org/Pages/FCAPRISAStudies (accessed 24 October 2018).

35. Centre for the AIDS Programme of Research in South Africa. CAPRISA. CTU studies. https://www.caprisa.org/Pages/CTUStudies (accessed 24 October 2018).

36. Wits RHI. Areas of expertise. http://www.wrhi.ac.za/expertise (accessed 26 October 2018).
37. Wits RHI. Partners and donors. http://www.wrhi.ac.za/about/partners-donors (accessed 26 October 2018).

38. HIV Prevention Trials Network. HPTN 084. Study summary. https://www.hptn org/research/studies/hptn084 (accessed 26 October 2018).

39. Bhekisisa. When there was no list of free abortion clinics, we made our own. Here's how. https://bhekisisa.org/article/2017-11-10-00-mind-the-gap-only5-of-health-facilities-offer-abortions-heres-how-to-find-them (accessed 29 October 2018).

Accepted 22 May 2019. 